Fisheries

\title{
Estimation of the abundance of the sei whale Balaenoptera borealis in the central and eastern North Pacific in summer using sighting data from 2010 to 2012
}

\author{
Takashi Hakamada $^{1}$ (D) Koji Matsuoka ${ }^{1} \cdot$ Hiroto Murase $^{2} \cdot$ Toshihide Kitakado $^{3}$
}

Received: 28 December 2016 / Accepted: 23 July 2017 / Published online: 28 August 2017

(C) The Author(s) 2017. This article is an open access publication

\begin{abstract}
The abundance of the sei whale Balaenoptera borealis in the central and eastern North Pacific (north of $40^{\circ} \mathrm{N}$, south of the Alaskan coast including both the US and Canadian Exclusive Economic Zones between $170^{\circ} \mathrm{E}$ and $135^{\circ} \mathrm{W}$ ), from July to August, was estimated by the line transect method using sighting data obtained during the 2010-2012 International Whaling Commission-Pacific Ocean Whale and Ecosystem Research cruises. The probability of detecting whales at a perpendicular distance from the transect was estimated using two different models: hazard rate and half-normal models. Because the difference in Akaike's information criterion between the two models was small, the Akaike weighted average of the two models was taken, which gave an estimated abundance of 29,632 (coefficient of variation, 0.242 ; 95\% confidence interval, 18,576-47,267). This is the first abundance estimate of sei whales in this region based on systematic sighting survey
\end{abstract}

Takashi Hakamada

hakamada@cetacean.jp

Koji Matsuoka

matsuoka@cetacean.jp

Hiroto Murase

muraseh@affrc.go.jp

Toshihide Kitakado

kitakado@kaiyodai.ac.jp

1 Institute of Cetacean Research, 4-5 Toyomi-cho, Chuo-ku, Tokyo 104-0055, Japan

2 National Research Institute of Far Seas Fisheries, Japan Fisheries Research and Education Agency, 2-12-4 Fukuura, Kanazawa, Yokohama, Kanagawa 236-8648, Japan

3 Tokyo University of Marine Science and Technology, 4-5-7 Konan, Minato-ku, Tokyo 108-8477, Japan data, which contributes to an understanding of the current status of this species.

Keywords Line transect sampling - Baleen whales . Distance sampling method $\cdot$ Cetacean $\cdot$ Model selection

\section{Introduction}

The sei whale Balaenoptera borealis is the third largest baleen whale, and typically exhibits a body length of $15 \mathrm{~m}$ and a weight of $20 \mathrm{t}$. It is distributed in temperate waters of both hemispheres, including the North Pacific [1,2]. This whale was targeted by commercial whalers, especially from the late 1950s to the mid-1970s, after numbers of the larger blue whale Balaenoptera musculus and fin whale Balaenoptera physalus had been depleted, but its harvesting was banned by the International Whaling Commission (IWC) in the North Pacific in 1975, in the Southern Hemisphere in 1979, and in the North Atlantic in 1989. Efforts at a crude estimation of its abundance in the North Pacific in 1963 and 1974 were attempted using various assessment models based on historical catches, catch per unit effort, and sighting rate data, leading to estimates of 42,000 and 8,600 individuals, respectively, which were the average of the results using various assessment models [3]. More recently, the abundance of whales has been estimated based on line transect sampling using data obtained by a systematically designed sighting survey conducted independently from fisheries. Line transect sampling is a distance sampling method in which abundance is estimated from a sample of perpendicular distances from tracklines to whales [4]. However, no attempt at this method was made in the North Pacific before 1974. Since the ban on commercial whaling, the status of the population of sei 
whales has rarely been studied because of a scarcity of data [5].

Recently, results of studies on sei whales using data obtained during the second phase of the Japanese Whale Research Program under special permit in the western North Pacific (JARPNII) from 2000 to 2016 have been reported, i.e., on stock structure [6], spatial distribution $[7,8]$, and feeding ecology $[9,10]$. The sei whale was one of the target species of the program along with the common minke Balaenoptera acutorostrata and Bryde's whale Balaenoptera edeni [11]. Systematically designed sighting surveys were conducted under the program to estimate the abundance of these species based on line transect sampling. The abundance estimates of sei whales distributed in the survey area in early summer (May-June) in 2011 and 2012 and in late summer (July-September) in 2008 were 2,988 and 5,086, respectively [11]. Note that the southern, northern, eastern, and western boundaries of the survey area of JARPNII were $35^{\circ} \mathrm{N}$, the boundary of the exclusive economic zone (EEZ) claimed by countries other than Japan, $170^{\circ} \mathrm{E}$, and the eastern coastline of Japan, respectively.

Several sighting surveys, which had been designed to estimate systematically the abundance of whales based on line transect sampling, were conducted in the coastal areas of the eastern North Pacific in the 2000s, although they were not designed specifically for sei whales. The abundance of sei whales in the waters of California, Oregon, and Washington to a distance from the coast of 300 nautical miles, was estimated as 126 individuals, based on the unweighted geometric mean of the 2005 and 2008 estimates [12]. Only one sighting of a sei whale was made in the surveys conducted in British Columbia's coastal waters in the summers of 2004, 2005, and 2008 and spring/fall of 2007 [13]. In addition, no sei whales were sighted in surveys conducted off western Alaska (within the 1000-m isobath) and the central Aleutian Islands (as far as $85 \mathrm{~km}$ offshore) in the summer of 2001-2003 [14].

The IWC has conducted a dedicated whale sighting survey program, Pacific Ocean Whale and Ecosystem Research (IWC-POWER), since 2010 to contribute information on the abundance and trends in abundance of populations of large whales and to explain any such identified trends [15]. A number of priority species and topics for this program were identified and high priority was assigned to sei whales [16].

Abundance is fundamental information for understanding the status of whales. However, the abundance of sei whales in offshore areas of the central and eastern North Pacific has never been estimated based on line transect sampling. The objective of this paper was to obtain such an estimate using the 2010-2012 IWC-POWER data.

\section{Materials and methods}

The survey procedures were carefully designed and agreed by the IWC Scientific Committee (IWCSC). Details of the procedures of the 2010-2012 IWC-POWER are described in the corresponding reports of the meeting for planning the surveys [17-19]. The procedures directly relevant to this analysis are presented here.

The 2010-2012 IWC-POWER was conducted north of $40^{\circ} \mathrm{N}$, south of the Aleutian Islands, and between $170^{\circ} \mathrm{E}$ and $135^{\circ} \mathrm{W}$ (Fig. 1). Although the IWC-POWER was also conducted to the south of $40^{\circ} \mathrm{N}$ in 2013 and 2014, the obtained data were not considered in this analysis because only one sighting of a sei whale was made in these 2 years [20]. Table 1 depicts the survey area (northern and southern strata) and survey periods in 2010, 2011, and 2012. In 2010, a part of the northern stratum within the US EEZ was surveyed first, and then, the rest of the northern stratum and southern stratum in the high seas were surveyed (Fig. 2a). As shown in Fig. 2a, some of the northern stratum was surveyed after the survey in the southern stratum had started. Owing to this, the survey periods in the northern and southern strata overlapped.

The research vessels Kaiko-Maru [860 gross tonnage (GT)] and Yushin-Maru No. 3 (742 GT) were engaged in the surveys in 2010 and 2011-2012, respectively. The survey was conducted during daytime from $1 \mathrm{~h}$ after sunrise to $1 \mathrm{~h}$ before sunset. The survey vessels traveled between 10.0 and 10.5 knots along the survey tracklines during the survey hours. Surveying was conducted when the visibility was 2.0 nautical miles or more, the wind speed was 20 knots or less, and the Beaufort wind force scale was less than 6 .

Tracklines were designed systematically in each stratum following the principles outlined in the IWC Scientific Committee's Requirements and Guidelines for

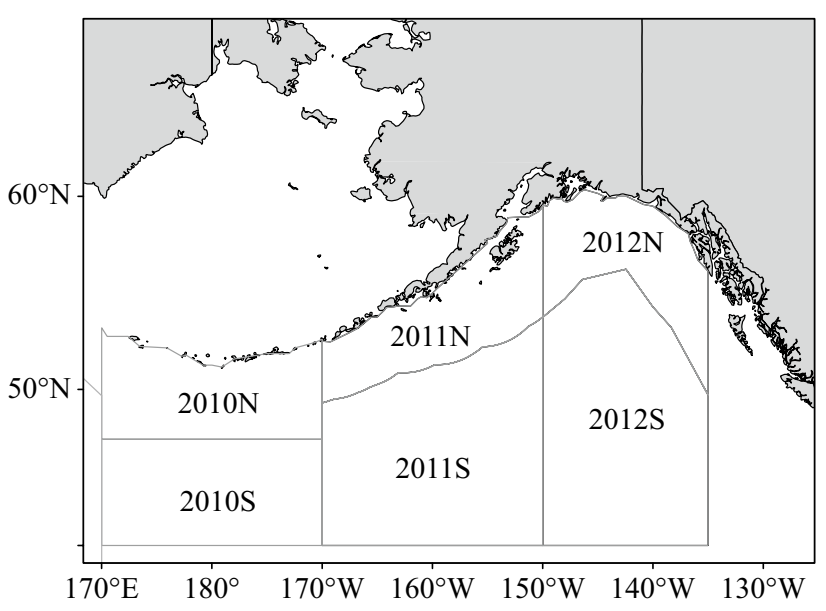

Fig. 1 Areas of the surveys conducted in the central and eastern North Pacific 2010-2012 
Table 1 Strata boundaries, survey periods and survey coverage (i.e., proportion of tracklines actually surveyed to planned survey tracklines) for each stratum during 2010 2012 International Whaling Commission-Pacific Ocean Whale and Ecosystem Research (IWC-POWER) cruises

\begin{tabular}{llllllll}
\hline Year & Strata & \multicolumn{2}{l}{ Strata boundary } & & Survey period & $\begin{array}{l}\text { Survey } \\
\text { coverage } \\
(\%)\end{array}$ \\
\cline { 3 - 5 } & & North & South & West & East & & 34 \\
\hline 2010 & Northern & Aleutian Is. & $47^{\circ} \mathrm{N}$ & $170^{\circ} \mathrm{E}$ & $170^{\circ} \mathrm{W}$ & 8 July-20 August $2010^{\mathrm{a}}$ & 34 \\
& Southern & $47^{\circ} \mathrm{N}$ & $30^{\circ} \mathrm{N}$ & $170^{\circ} \mathrm{E}$ & $170^{\circ} \mathrm{W}$ & 18 July-25 August $2010^{\mathrm{a}}$ & 70 \\
2011 & Northern & Aleutian Is. & US EEZ & $170^{\circ} \mathrm{W}$ & $150^{\circ} \mathrm{W}$ & 21 July-1 August 2011 & 58 \\
& Southern & US EEZ & $30^{\circ} \mathrm{N}$ & $170^{\circ} \mathrm{W}$ & $150^{\circ} \mathrm{W}$ & 2-31 August 2011 & 78 \\
2012 & Northern & Aleutian Is. & US EEZ & $150^{\circ} \mathrm{W}$ & $135^{\circ} \mathrm{W}$ & 24 July-3 August 2012 & 80 \\
& Southern & US EEZ & $30^{\circ} \mathrm{N}$ & $150^{\circ} \mathrm{W}$ & $135^{\circ} \mathrm{W}$ & $3-30$ August 2012 & 85 \\
\hline
\end{tabular}

Is. Islands, EEZ exclusive economic zone

${ }^{\text {a }}$ Survey periods in northern and southern strata overlap for reasons given in the main text
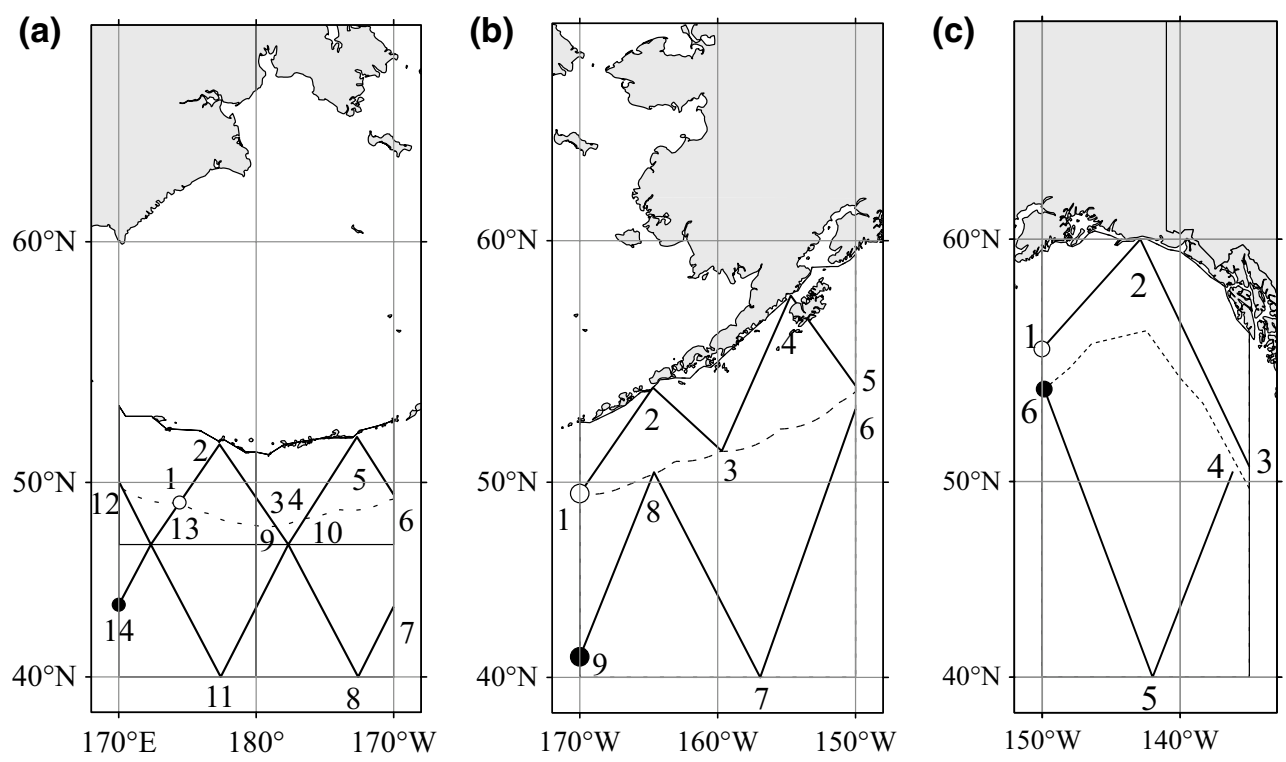

Fig. 2 Planned trackline (bold black lines), start point (open circle), end point (black circle), and survey order (numbers) for 2010 (a), 2011 (b), and 2012 (c) in the surveys conducted in the central and eastern North Pacific conducted from 2010 to 2012. Areas in exclu- sive economic zones (EEZs) were surveyed first, followed by areas in the high seas, except in 2010. Numbers indicate the order of way points that vessels go through. Broken lines indicate the boundaries of EEZs of relevant countries
Surveys [21]. Planned tracklines and the survey order for 2010-2012 IWC-POWER are shown in Fig. 2a-c. In 2010 , legs were allocated at $5^{\circ}$ longitudinal width in the northern and southern strata. The starting points of the tracklines were selected at random along the lines of longitude. In 2011 and 2012, a random start point for survey tracks, the same as that in the 2010 IWC-POWER cruise, was used. Following the IWCSC survey guidelines [21], equally spaced zigzag lines were designed in the northern and southern strata, so that every location within the study area had an equal probability of being sampled. The zigzag tracklines were systematically designed using the software Distance version 6.0, which offers functions to design a survey and estimate abundance based on line transect sampling [22]. The details of the survey design method are described elsewhere [23]. Sei whales were expected to undertake their northern-bound migration during the survey period. To avoid double counting (i.e., counting migrating individuals twice or more in the survey), the northern stratum was surveyed first, followed by the southern stratum.

Two and three observers were allocated to the top barrel (crow's nest) and upper bridge, at heights of $19.5 \mathrm{~m}$ and about $10 \mathrm{~m}$, respectively. In 2010, an observer was allocated to an additional platform $14.5 \mathrm{~m}$ above sea level. Immediately after a sighting was made from the barrel, the observer informed observers on the upper bridge of his/her estimate of the distance and angle to the sighting and continued searching for the whale schools. The observers on the upper bridge attempted to confirm the species and school size before the 
school passed abeam of the vessel. If the observers could not make a confirmation when the school passed abeam of the vessel, the vessel started approaching the whales to confirm the species and the school size. If a sighting occurred while the vessel was approaching the whales, this sighting was not used for abundance estimation. The species and the school size were confirmed for all sightings of schools of sei whales (i.e., vessels approached the whales close enough to confirm the species and the number of whales) used in this analysis. All the observers and researchers used $7 \times 50$ binoculars for searching. The sighting distance was limited to 3.0 nautical miles at a perpendicular distance from the trackline. The distance was estimated using reticles in the binoculars, while the angle was estimated using angle boards at equipped observation booths. The estimated distance and angle were corrected based on the results of the angle and distance estimation experiment conducted by the observers. In the experiment, an observer estimated the angle and distance from the vessels to an experimental buoy, and the results were compared with the actual angle and distance. Perpendicular distances from the tracklines to the schools were calculated using the distance and angle (Fig. 3).

To deal with the possibility of the detection probability differing among the detections, abundance and its variance-covariance matrix were estimated based on a Horvitz-Thompson-like estimator, which was applied to estimate the abundance of wildlife animals [24, 25], expressed by Eqs. 1 and 2, respectively [22, 26]:

$$
\begin{aligned}
& N=\frac{A}{2 W L} \sum_{i=1}^{n} \frac{s_{i}}{p\left(z_{i}\right)} \\
& =\frac{A}{2 L} \sum_{i=1}^{n} s_{i} \hat{f}\left(0 \mid z_{i}\right),
\end{aligned}
$$

where $N$ is the abundance estimate, $A$ is the area of the surveyed area (nautical miles ${ }^{2}$ ), $W$ is the truncation distance (3.0 nautical miles in perpendicular distance from tracklines), $L$ is the searching distance (nautical miles), $n$ is the number of schools detected within the perpendicular

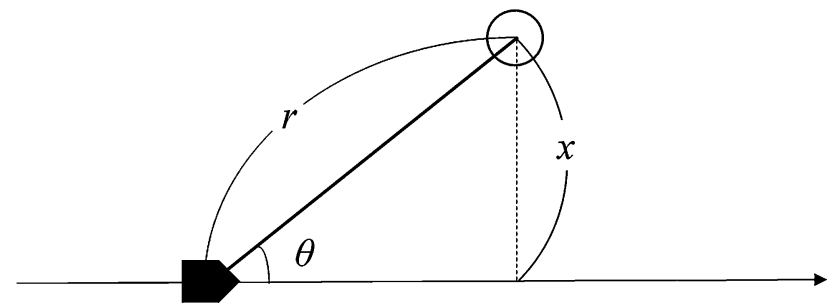

Fig. 3 Illustration of perpendicular distance (broken line; $x$ ) using the distance $(r)$ from observers (black pentagon) to whales (open circle) and the angle $(\theta)$ distance $W, s_{i}$ is the school size of the $i$ th detection, $p\left(z_{i}\right)$ is the probability that school $i$ is detected given that it is within the perpendicular distance $W$ and given the covariate vector $z_{i}$ (Eq. 5), $f\left(0 \mid z_{i}\right)$ is the conditional probability density function of distance 0 given covariate $z_{i}$, and

$$
\begin{aligned}
& \operatorname{var}(N)=\left(\frac{A}{2 W L}\right)^{2} \\
& \quad\left\{\frac{1}{L(K-1)} \sum_{k=1}^{K} l_{k}\left(\frac{N_{C k}}{l_{k}}-\frac{N_{C}}{L}\right)^{2}+\sum_{m=1}^{r} \sum_{m^{\prime}=1}^{r} \frac{\partial N_{C}}{\partial \theta_{m}} \frac{\partial N_{C}}{\partial \theta_{m^{\prime}}} H_{m m^{\prime}}^{-1}(\theta)\right\}
\end{aligned}
$$

where $\operatorname{var}(N)$ is the variance of $N, K$ is the number of transects, $l_{k}$ is the searching distance in the $k$ th transect, $N_{C k}$ is the abundance estimate in the $k$ th transect in the covered region $C$ (within 3 nautical miles from the trackline surveyed), $N_{C}$ is the abundance estimate in the covered region $C$, and $H_{m n}^{-1}(\theta)$ is the $m m$ th element of the inverse Hessian matrix of detection function for covariate $\theta$.

We fitted the hazard rate (Eq. 3) and half-normal models (Eq. 4) as candidate models for the probability detection function using the multiple covariate distance sampling (MCDS) engine in the Distance program [22, 26]:

$g\left(x, z_{i}\right)=1-\exp \left\{-(x / a \exp (\text { Size }+ \text { Beaufort }+ \text { Year }))^{-b}\right\}$

$g\left(x, z_{i}\right)=\exp \left[-x^{2} / 2 a^{2} \exp \{2(\right.$ Size + Beaufort + Year $\left.)\}\right]$,

where $x$ is the perpendicular distance, $z_{i}$ is a vector of covariates (i.e., size, Beaufort, and year), $a(a>0)$ and $b(b \geq 1)$ are parameters [restriction of parameters is required so that Eqs. 3 and 4 are defined mathematically], size is the observed school size, Beaufort is the categorical variable for Beaufort scale (good, 0-3, bad, 4-5), and year is the categorical variable for year. The covariates were used in the models with an assumption that detectability depends on them. In the Distance program, other detection function models such as the uniform and negative exponential models can be considered $[4,27,28]$. However, the uniform detection function was not considered because the assumption that the detection probability is constant regardless of the perpendicular distance is hardly valid, as indicated by previous observations and analysis for whale abundance estimation. The negative exponential function was also not considered because its use is not recommended as it has no clear "shoulder." For this analysis, we assumed that $g\left(0, z_{i}\right)=1$ for any $z_{i}$ (i.e., all schools on the trackline are detected, irrespective of the covariates considered). Akaike's information criterion (AIC) was thus used to select the best model for the hazard rate and half-normal models (i.e., the model minimizing AIC) to estimate the probability that school $i$ is detected $p\left(z_{i}\right)$ : 
$p\left(z_{i}\right)=\frac{1}{W} \int_{0}^{W} g\left(x, z_{i}\right) \mathrm{d} x=\frac{1}{W} \hat{f}\left(0 \mid z_{i}\right)$.

To estimate detection functions (Eqs. 3 and 4), the likelihood function was expressed [4] as follows:

$L_{x \mid z}=\prod_{i=1}^{n} f_{x \mid z}\left(x_{i} \mid z_{i}\right)$

Here, $f_{x \mid z}\left(x_{i} \mid z_{i}\right)$ is the probability density function of $x_{i}$ conditional on the covariate $z_{i}$ :

$f_{x \mid z}\left(x_{i} \mid z_{i}\right)=\frac{g\left(x_{i}, z_{i}\right)}{\mu\left(z_{i}\right)}$

where

$\mu\left(z_{i}\right)=\int_{0}^{W} g\left(x, z_{i}\right) \mathrm{d} x$

As $g\left(0, z_{i}\right)=1$ according to the assumption mentioned above, if we set $x_{i}=0$ in Eq. 7, it can be expressed as follows:

$\mu\left(z_{i}\right)=\frac{1}{f_{x \mid z}\left(0 \mid z_{i}\right)}$.

The initial values of the parameters were set at default values in Distance, and if the parameters did not converge, the program would change the initial values and start maximizing likelihood again. If necessary, this would be repeated within the predetermined number of iterations.

Perpendicular distance was not binned in the fitting detection function because the selection of a cut-off point can affect the results of model selection and parameter estimates of detection function. $\chi^{2}$ statistics were calculated for each detection function to see the goodness of fit for the models [27]. A quantile-quantile (QQ) plot was used to determine whether the empirical cumulative distribution function (cdf) and fitted cdf are similar distributions, indicating a good fit [29].

The effects of the inclusion of covariates in the detection functions on abundance estimates were examined by comparing the abundance estimate corresponding to the best model of the detection function with those corresponding to other detection functions. Averaged abundance estimates using Akaike weights $\left(w_{j}\right)$ [30] were also examined in the case where the difference in AIC among models was small. Buckland et al. [31] applied $w_{j}$ to deal with the case that a different choice of model yields different estimates of abundance even when the difference in AIC between two models is small:

$w_{j}=e^{-\frac{1}{2} \Delta \mathrm{AIC}_{j}}$, where

$\Delta \mathrm{AIC}_{j}=\mathrm{AIC}_{j}-\mathrm{AIC}_{\min }$.

Here, $\mathrm{AIC}_{j}$ is the $\mathrm{AIC}$ for model $j$ and $\mathrm{AIC}_{\min }$ is the $\mathrm{AIC}$ for the best model. The weighted average over the abundance estimates, $N_{w}$, and its SE are given as follows:

$N_{w}=\sum_{j=1} \tilde{w}_{j} N_{j}$

$\operatorname{SE}\left(N_{w}\right)=\sqrt{\sum_{j=1} \tilde{w}_{j}^{2} \operatorname{var}\left(N_{j}\right)+2 \sum_{j \neq j^{\prime}} \tilde{w}_{j} \tilde{w}_{j^{\prime}} \operatorname{cov}\left(N_{j}, N_{j^{\prime}}\right)}$,

where $\tilde{w}_{j}$ and $\tilde{w}_{j^{\prime}}$ are the normalized $w_{j}$ for models $j$ and $j^{\prime}$ expressed by the equation below:

$\tilde{w}_{j}=\frac{w_{j}}{\sum_{j=1} w_{j}}$.

Two average weighted estimates of abundance were examined for comparison. One was the average abundance estimated by the hazard rate and half-normal models with the lowest AIC values (i.e., the best models). We consider this estimate to be a reference case. The other was the average over 16 estimates for all of the detection functions examined (see "Results" for details).

\section{Results}

The searching distance and the number of schools of sei whales within 3 nautical miles from the trackline for each stratum used in the analysis are summarized in Table 2. Survey coverage (the proportion of searching distance to planned distance) for each stratum during the 2010-2012 IWC-POWER surveys is shown in Table 1. Figure 4 shows the plot of surveyed tracklines and the sighting positions of sei whales during the 2010-2012 IWC-POWER surveys. Most sei whales occurred in the southern stratum in the surveys.

Table 3 gives the AIC for each candidate model examined in this study. Among the models, the half-normal model with no covariates was selected as the best model to estimate the detection probability. An estimate of parameter $a$ and its SE of the best model were 1.619 and 0.152 , respectively, for the detection function selected by AIC. Averaged detection probability over all sightings was 0.633 [coefficient of variation $(\mathrm{CV})=0.067]$. Figure 5 shows the detection function and observed frequency of detection of the best model. The Chi-square statistic of the best model was 17.534, with 11 degrees of freedom $(p=0.093)$. Figure 6 shows a QQ plot of the detection function, which suggests that points fall almost 
Table 2 Abundance estimates $(N)$ of the sei whales and their coefficient of variation (CV) for each stratum based on 2010-2012 IWC-POWER cruises from July to August for the best model of the detection function

\begin{tabular}{|c|c|c|c|c|c|c|c|c|c|c|c|}
\hline Year & Stratum & $A$ (nautical miles ${ }^{2}$ ) & $L$ (nautical miles) & $n_{s}$ & $n_{w}$ & $n_{w} / L$ & $\mathrm{CV}\left(n_{w} / L\right)$ & $N$ & $\mathrm{CV}(N)$ & $95 \%$ CI LL & $95 \%$ CI UL \\
\hline \multirow[t]{2}{*}{2010} & Northern & 238,627 & 490.5 & 4 & 4 & 0.008 & 0.502 & 512 & 0.507 & 185 & 1,415 \\
\hline & Southern & 365,244 & 1325.7 & 45 & 84 & 0.063 & 0.441 & 6,093 & 0.446 & 2,520 & 14,733 \\
\hline \multirow[t]{2}{*}{2011} & Northern & 193,560 & 723.8 & 0 & 0 & - & - & 0 & - & - & - \\
\hline & Southern & 569,167 & 1674.0 & 37 & 72 & 0.043 & 0.452 & 6,445 & 0.457 & 1,066 & 38,985 \\
\hline \multirow[t]{2}{*}{2012} & Northern & 142,427 & 767.5 & 2 & 4 & 0.005 & 0.751 & 195 & 0.754 & 45 & 853 \\
\hline & Southern & 529,362 & 1358.6 & 74 & 136 & 0.100 & 0.337 & 13,952 & 0.343 & 6,927 & 28,099 \\
\hline Total & & $2,038,387$ & 6340.0 & 162 & 300 & 0.047 & 0.230 & 27,197 & 0.236 & 16,841 & 43,923 \\
\hline
\end{tabular}

$A$ Area of the surveyed area, $n_{s}$ number of schools detected within a perpendicular distance of 3.0 nautical miles, $n_{w}$ number of individuals detected within a perpendicular distance of 3.0 nautical miles, $L$ searching distance, $C I$ confidence interval, $L L$ lower limit, $U L$ upper limit

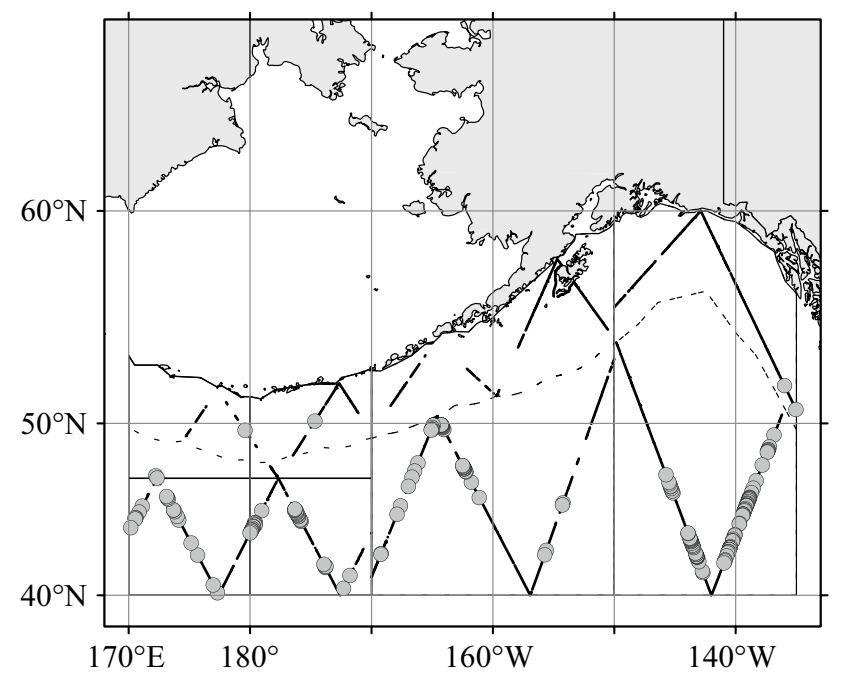

Fig. 4 Plot of the surveyed trackline (black lines) and position of primary sightings of sei whales (circles) in surveys conducted in the central and eastern North Pacific conducted from 2010 to 2012

close to the 1-1 line, indicating that the model provides a good fit [29]. Table 2 shows abundance in each stratum based on the best model. The total abundance estimate was 27,197 (CV = 0.236) for the best model.

Table 3 also shows a difference in abundance estimates and their CVs for each detection function examined, and suggests that the abundance estimate did not differ markedly irrespective of the covariates selected. However, point abundance estimates between the hazard rate and halfnormal models differed, although these differences were not statistically significant. For example, the abundance estimate for the best model among the hazard rate models examined (i.e., hazard rate model with no covariates) was 33,725 with a CV of 0.281 . Using abundance estimates, their CV, and AIC, as shown in Table 3, the average of the two abundance estimates (reference case; i.e., the average abundance estimated by the hazard rate and half-normal
Table 3 Abundance estimates $(N)$ for sei whales, their CV, Akaike's information criterion (AIC), and difference in AIC from the best model estimate $(\triangle \mathrm{AIC})$ for each model of the detection function

\begin{tabular}{llllll}
\hline Model & Covariate & $N$ & $\mathrm{CV}(N)$ & AIC & $\Delta$ AIC \\
\hline HR & $S+B+Y$ & 31,381 & 0.258 & 327.7 & 1.78 \\
& $S+B$ & 31,633 & 0.264 & 327.8 & 1.87 \\
& $S+Y$ & 30,652 & 0.262 & 328.1 & 2.18 \\
& $B+Y$ & 35,203 & 0.288 & 327.7 & 1.86 \\
& $S$ & 31,146 & 0.266 & 327.5 & 1.62 \\
& $B$ & 34,878 & 0.282 & 327.6 & 1.72 \\
& $Y$ & 33,454 & 0.283 & 327.7 & 1.84 \\
& None & 33,725 & 0.281 & 326.9 & 1.04 \\
& $S+B+Y$ & 26,145 & 0.225 & 326.9 & 1.03 \\
& $S+B$ & 25,921 & 0.229 & 327.5 & 1.60 \\
& $S+Y$ & 25,907 & 0.230 & 327.4 & 1.48 \\
& $B+Y$ & 27,287 & 0.230 & 326.5 & 0.64 \\
& $S$ & 25,943 & 0.234 & 326.7 & 0.83 \\
& $B$ & 27,381 & 0.234 & 327.2 & 1.35 \\
& $Y$ & 27,024 & 0.234 & 326.5 & 0.63 \\
& None & 27,197 & 0.236 & 325.9 & 0.00 \\
\hline
\end{tabular}

$H R$ Hazard rate, $H N$ half-normal, $S$ school size, $B$ Beaufort scale wind speed, $Y$ year

models with the lowest AIC values for each model) by $w_{j}$ was 29,632 (reference case) and its $\mathrm{CV}$ is 0.242 . The average over 16 abundance estimates listed in Table 3 was 29,133 with a CV of 0.231 . The averaged abundance estimate was similar to that of the reference case. For the average over 16 estimates, the difference in abundance estimate from the reference case was $-1.7 \%$ of the reference case. Therefore, there was no substantial difference among the averaged abundance estimates, and thus, the averaged abundance estimate was robust, irrespective of whether covariates were taken into account in the probability detection function. 


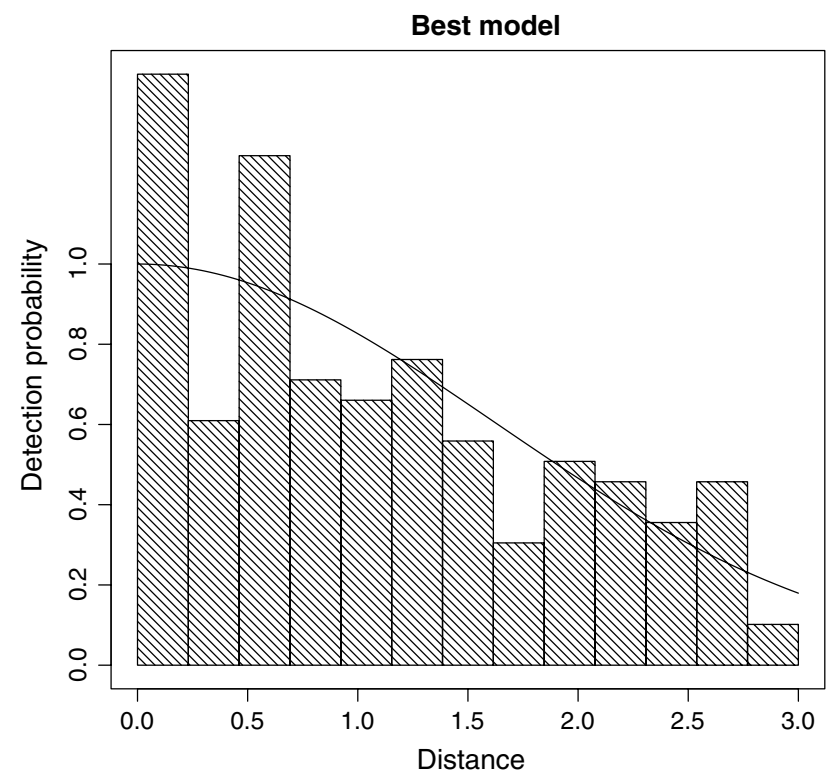

Fig. 5 Plot of the estimated detection function (black curve) fitted to the relative frequency of the detections as a function of perpendicular distance (nautical miles) from the trackline for half-normal model with no covariates (i.e., the best model)

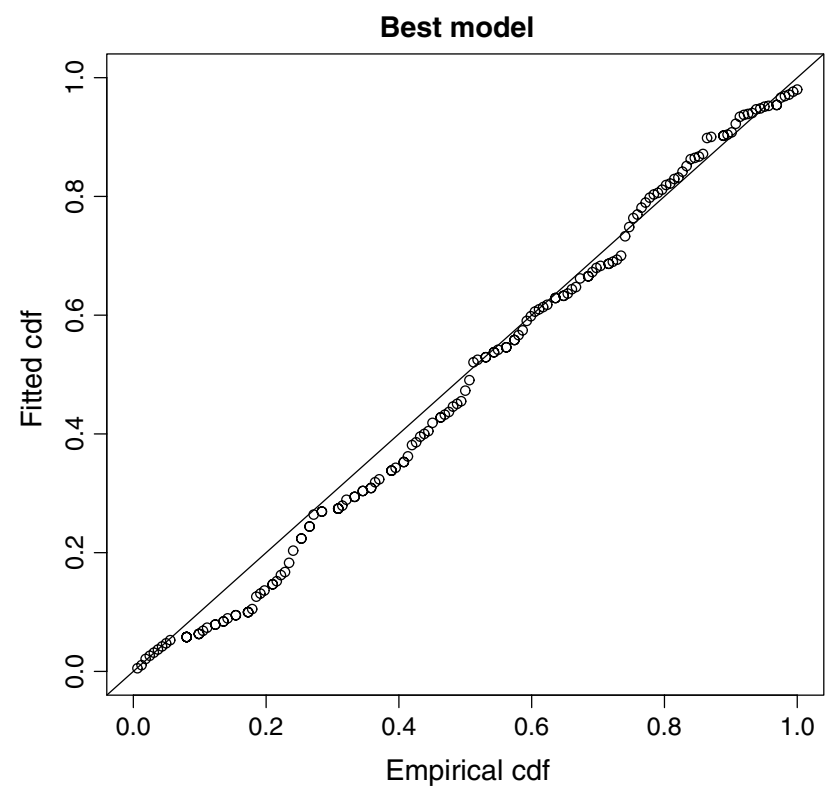

Fig. 6 Quantile-quantile plot of detection functions for the halfnormal model with no covariates (the best model), which plots the empirical cumulative distribution function (cdf) versus the fitted cdf

\section{Discussion}

This study provides the first ever abundance estimate of sei whales in the central and eastern North Pacific based on line transect sampling. A genetic study suggested that sei whales in the North Pacific consist of a single stock [32]. As noted earlier, the abundance of sei whales in the western North Pacific in late summer in 2008 was estimated at 5,086 individuals. The abundance of sei whales in the North Pacific is 34,718 individuals if we add this estimate to the weighted average estimate of 29,632. It appears that the abundance of sei whales in the North Pacific increased from 1974 (8,600 individuals), although a direct comparison between these estimates cannot be made because of the difference in analysis methods. An in-depth assessment of sei whales in the North Pacific is required to assess their population status. An in-depth assessment can be defined as an in-depth evaluation of the status of target stocks in the light of management objectives and procedures, and it should include the examination of current stock size, recent population trends, carrying capacity, and productivity [33]. Abundance estimated in our study will contribute to such an assessment of sei whales in the North Pacific.

Past spatial distribution inferred from commercial catch positions [34] and sighting positions of a Japanese scouting vessel [35] showed that sei whales occurred at a high density in the northern strata of our study (i.e., the Aleutian Islands and the Gulf of Alaska). In contrast, we had only a few sightings there. There are several possible reasons for this discrepancy:

1. The number of sei whales did not fully recover after the ban on commercial whaling.

2. Interspecific competition with other baleen whales such as the fin whale and humpback whale Megaptera novaeangliae, which are distributed in the same area.

3. The timing of our survey in the area did not cover the peak northern-bound migration season of sei whales.

However, it is difficult to draw any conclusions about the discrepancy at this stage because of the lack of an appropriate data set to test the possible reasons. These points should be taken account when designing future surveys. Conventional distance sampling and MCDS, which is its extension, can only give abundance estimates at a coarse scale (e.g., at a scale of a survey area or strata within it). However, the spatial distribution of sei whales is heterogeneous with respect to environmental variables as reported in the North Pacific [7, 8, 36] and North Atlantic [37, 38]. A spatial modeling framework to estimate abundance at a fine scale (e.g., $10 \times 10-\mathrm{km}$ grid) has been developed [39], and it is now implemented in a statistical software package [40]. The application of such a model to our data will enhance the understanding of the distribution ecology of this species.

In the case of the common minke whale in the North Atlantic, the Beaufort scale affects the detectability [41]. The Beaufort scale had been expected to be a covariate of detectability in this analysis, but the detection function with no covariate was the best model among the half-normal and 
hazard rate models. There are two possible reasons why the Beaufort scale did not substantially affect detectability for the sei whales in this study. Sei whales have body lengths of approximately $15 \mathrm{~m}$ on average [1] and common minke whales in North Atlantic have body lengths at physical maturity of approximately $8.5-8.8 \mathrm{~m}$ for females and $7.8-8.2 \mathrm{~m}$ for males [42]. One possible reason why the Beaufort scale did not substantially affect detectability is because sei whales can be detected even if the Beaufort scale is high (i.e., under strong wind) due to their larger size (hence the size of blow is also larger) than minke whales. Another possible reason is because the effect was not detected from the data set used in this study even though it actually exists. To investigate which possibility is more likely, other data of sei whales can be examined.

Our survey procedures were designed so that the following assumptions were met to estimate abundance based on line transect sampling:

1. Whales are distributed independently of the lines.

2. Objects are detected at their initial location.

3. Distances to whales are exactly measured.

4. All whales on the line are detected $[g(0)=1$ or $g(0$, $\left.z_{i}\right)=1$ if the detectability is conditional on the covariate].

Regarding assumption 4, it has been reported that the $g(0)$ estimate of this species in the eastern North Pacific for each Beaufort state relative to Beaufort zero ranged from 0.270 to 0.804 , with an average of 0.73 [43]. In our study, it is assumed that $g\left(0, z_{i}\right)=1$, but if not, this assumption can cause abundance underestimation. It is better to test whether our assumption can hold when an appropriate data set is available.

At this stage, there is no dataset to estimate additional variance for the sei whale abundance. Additional variance (i.e., process error) is the variability in the successive abundance estimates due to inter-annual change in the distribution of whale populations in the surveyed areas [44]. Additional variance could be estimated if a survey were conducted in the same area as that covered in 2010-2012 using approaches described elsewhere [41, 45, 46], which could lead to further progress in estimating the variance of abundance by taking into account the inter-annual variation.

In the case where one model can be clearly regarded as the best, or in the case where abundance estimates do not differ among models, there is no problem in choosing an abundance estimate for the best model. In this study, point abundance estimates between the hazard rate and halfnormal models differed, while the difference in the AIC for the models was small (Table 3). In the case where the abundance differs among the candidate models, which was similar to the case in our study, basing a prediction on a single selected model can lead to inaccurate results [30]. The Akaike weighted average of abundance estimates can avoid this risk. The averaged abundance could substantially change depending on sets of abundance estimates to be averaged over. If so, we cannot determine which averaged abundance is most reliable. In this study, two averaged abundance estimates were not substantially different. However, the variance of the averaged abundance estimate does not consider model selection uncertainty for the detection function. This can potentially cause underestimation of the variance for the abundance estimate. Investigation of the method of estimating the variance should be undertaken in future work.

Acknowledgments The authors would like to thank the captain, crew, and international researchers onboard the Kaiko-Maru and the YushinMaru no. 3 for their hard work during the survey. They would also like to thank the IWC Secretariat for kindly providing IWC-POWER sighting data for North Pacific sei whales and Marion Hughes, IWC, for her hard work on validating the IWC-POWER sighting data. We would like to thank the editor and two anonymous reviewers for their valuable suggestions and comments which improved an earlier version of this paper.

Open Access This article is distributed under the terms of the Creative Commons Attribution 4.0 International License (http://creativecommons.org/licenses/by/4.0/), which permits unrestricted use, distribution, and reproduction in any medium, provided you give appropriate credit to the original author(s) and the source, provide a link to the Creative Commons license, and indicate if changes were made.

\section{References}

1. Horwood J (1987) The sei whales: population biology, ecology and management. Croom Helm, London

2. Horwood J (2009) Sei whale: Balaenoptera borealis. In: Perrin WF, Würsig B, Thewissen JGM (eds) Encyclopedia of marine mammals, 2nd edn. Academic Press, London, pp 1001-1003

3. Tillman MF (1977) Estimates of population size for the North Pacific sei whale. Rep Int Whal Comm Special Issue 1:98-106

4. Buckland ST, Rexstad EA, Marques TA, Oedekoven CS (2015) Distance sampling: methods and applications. Springer International, Switzerland

5. Prieto R, Janiger D, Silva MA, Waring GT, Gonçalves JM (2012) The forgotten whale: a bibliometric analysis and literature review of the North Atlantic sei whale Balaenoptera borealis. Mamm Rev 42:235-272

6. Kanda N, Goto M, Pastene LA (2006) Genetic characteristics of western North Pacific sei whales, Balaenoptera borealis, as revealed by microsatellites. Mar Biol 8:86-93

7. Murase H, Hakamada T, Matsuoka K, Nishiwaki S, Inagake D, Okazaki M, Tojo N, Kitakado T (2014) Distribution of sei whales (Balaenoptera borealis) in the subarctic-subtropical transition area of the western North Pacific in relation to oceanic fronts. Deep Sea Res II 107:22-28

8. Sasaki H, Murase H, Kiwada H, Matsuoka K, Mitani Y, Saitoh S (2013) Habitat differentiation between sei (Balaenoptera borealis) and Bryde's whales (B. brydei) in the western North Pacific. Fish Oceanogr 22:496-508

9. Konishi K, Tamura T, Isoda T, Okamoto R, Hakamada T, Kiwada H, Matsuoka K (2009) Feeding strategies and prey consumption 
of three baleen whale species within the Kuroshio-Current extension. J North Atl Fish Sci 42:27-40

10. Watanabe H, Okazaki M, Tamura T, Konishi K, Inagake D, Bando T, Kiwada H, Miyashita T (2012) Habitat and prey selection of common minke, sei, and Bryde's whales in mesoscale during summer in the subarctic and transition regions of the western North Pacific. Fish Sci 78:557-567

11. International Whaling Commission (2017) Report of the Expert Panel of the final review on the western North Pacific Japanese Special Permit Programme (JARPNII) 22-26 February 2016, Tokyo, Japan. J Cetacean Res Manage 18(Suppl):527-592

12. Carretta JV, Oleson EM, Baker J, Weller DW, Lang AR, Forney KA, Muto MM, Hanson B, Orr AJ, Huber H, Lowry MS, Barlow J, Moore JE, Lynch D, Carswell L, Brownell Jr RL (2016) US Pacific marine mammal stock assessments: 2015. NOAA-TM-NMFS-SWFSC-561

13. Best BD, Fox CH, Williams R, Halpin PN, Paquet PC (2015) Updated marine mammal distribution and abundance estimates in British Columbia. J Cetacean Res Manage 15:9-26

14. Zerbini AN, Waite JM, Laake JL, Wade PR (2006) Abundance, trends and distribution of baleen whales off Western Alaska and the central Aleutian Islands. Deep Sea Res I 53:1772-1790

15. International Whaling Commission (2012) Report of the Scientific Committee. J Cetacean Res Manage 13(Suppl):1-74

16. International Whaling Commission (2011) Report of the Scientific Committee. J Cetacean Res Manage 12(Suppl):1-75

17. International Whaling Commission (2012) Report of the Workshop on Planning for an IWC co-ordinated North Pacific Research Cruise Programme, 28 September-1 October 2010, Tokyo, Japan. J Cetacean Res Manage 13(Suppl):369-392

18. International Whaling Commission (2013) Report of the Technical Advisory group (TAG) meeting on the short- and medium-term objectives and plans for the IWC-POWER Cruises. J Cetacean Res Manage 14(Suppl):341-356

19. International Whaling Commission (2014) Report of the Planning Meeting for the 2013 IWC-POWER Cruise, 25-26 October 2012, Tokyo, Japan. J Cetacean Res Manage 15(Suppl):423-436

20. International Whaling Commission (2016) Report of the Meeting of the IWC-POWER Technical Advisory Group (TAG), 8-10 October 2014, Tokyo, Japan. J Cetacean Res Manage 17(Suppl):443-458

21. International Whaling Commission (2012) Requirements and guidelines for conducting surveys and analysing data within the revised management scheme. J Cetacean Res Manage 15(Suppl):507-518

22. Thomas L, Buckland ST, Rexstad EA, Laake JL, Strindberg S, Hedley SL, Bishop JRB, Marques TA, Burnham KP (2010) Distance software: design and analysis of distance sampling surveys for estimating population size. J App Ecol 47:5-14

23. Strindberg S, Buckland ST (2004) Zigzag survey designs inline transect sampling. JABES 9:443-461

24. Innes S, Heide-Jorgensen MP, Laake JL, Laidre KL, Cleator HJ, Richard P, Stewart REA (2002) Surveys of belugas and narwhals in the Canadian High Arctic in 1996. NAMMCO Sci Publ 4:169-190

25. Marques TA, Thomas L, Fancy SG, Buckland ST (2007) Improving estimates of bird density using multiple covariate distance sampling. Auk 124:1229-1243

26. Marques FFC, Buckland ST, Borchers DL (2004) Covariate models for the detection function. In: Buckland ST, Anderson DR, Burnham KP, Laake JL, Borchers DL, Thomas L (eds) Advanced distance sampling. Oxford University Press, London, pp 31-47

27. Buckland ST, Anderson DR, Burnham KP, Laake JL (1993) Distance sampling: estimating abundance of biological populations. Chapman and Hall, New York
28. Buckland ST, Anderson DR, Burnham KP, Laake JL, Borchers DL, Thomas L (2001) Introduction to distance sampling: estimating abundance of biological populations. Oxford University Press, Oxford

29. Burnham KP, Buckland ST, Laake JL, Borchers DL, Marques TA, Bishop JRB, Thomas L (2004) Further topics in distance sampling. In: Buckland ST, Anderson DR, Burnham KP, Laake JL, Borchers DL, Thomas L (eds) Advanced distance sampling. Oxford University Press, London, pp 307-392

30. Burnham KP, Anderson DR (2002) Model selection and multimodel inference-a practical information theoretic approach, 2nd edn. Springer, New York

31. Buckland ST, Burnham KP, Augustin NH (1997) Model selection: an integral part of inference. Biometrics 53:603-618

32. International Whaling Commission (2017) Report of the IWC Scientific Committee. J Cetacean Res Manage 18(Suppl):1-109

33. International Whaling Commission (1987) Report of the Special Meeting of the Scientific Committee on Planning for a Comprehensive Assessment of Whale Stocks. Rep Int Whal Commn $37: 147-157$

34. Nasu K (1966) Fishery oceanographic study on the baleen whaling ground. Sci Rep Whales Res Inst 20:157-209

35. Miyashita T, Kato H, Kasuya T (1995) Worldwide map of cetacean distribution based on Japanese sighting data. National Research Institute of Far Seas Fisheries, Shizuoka, Japan

36. Gregr EJ, Trites AW (2001) Predictions of critical habitat for five whale species in the waters of coastal British Columbia. Can J Fish Aquat Sci 58:1265-1285

37. Skov H, Gunnlaugsson T, Budgell WP, Horne J, Nøttestad L, Olsen E, Søiland H, Víkingsson G, Waring G (2008) Small-scale spatial variability of sperm and sei whales in relation to oceanographic and topographic features along the Mid-Atlantic Ridge. Deep Sea Res II 55:254-268

38. Prieto R, Tobeña M, Silva MA (2016) Habitat preferences of baleen whales in a mid-latitude habitat. Deep Sea Res II. doi:10.1016/j.dsr2.2016.07.015

39. Hedley SL, Buckland ST, Borchers DL (1999) Spatial modelling from line transect data. J Cetacean Res Manage 1:255-264

40. Miller DL, Burt ML, Rexstad EA, Thomas L (2013) Spatial models for distance sampling data: recent developments and future directions. Methods Ecol Evol 4:1001-1010

41. Skaug HJ, Øien N, Schweder T, Bothun G (2004) Abundance of minke whales (Balaenoptera acutorostrata) in the Northeast Atlantic: variability in time and space. Can J Fish Aquat Sci 61:870-886

42. Perrin WF, Brownell RL Jr (2009) Minke Whales Balaenoptera acutorostrata and B. bonaerensis. In: Perrin WF, Würsig B, Thewissen JGM (eds) Encyclopedia of marine mammals, 2nd edn. Academic Press, London, pp 733-735

43. Barlow $\mathbf{J}(2015)$ Inferring trackline detection probabilities, $g(0)$, for cetaceans from apparent densities in different survey conditions. Mar Mamm Sci 31:923-943

44. International Whaling Commission (1996) Report of the Scientific Committee, annex D. Report of the Sub-committee on the management procedures. Rep Int Whal Commn 46:107-116

45. Cooke JG (1994) Analysis of inter-survey variability of IDCR minke whale abundance estimates ('process error'). Rep Int Whal Commn 44:90

46. Punt AE, Cooke JG, Borchers DL, Strindberg S (1997) Estimating the extent of additional variance for southern hemisphere minke whales from the results of the IWC/IDCR cruises. Rep Int Whal Commn 47:431-434 